\title{
Eosinophilic Esophagitis: A Rare Cause of Dysphagia: About A Case
}

\author{
Chait Yassine $^{1 *}$, Nacir Oussama, AitErrami Adil ${ }^{1}$, Samlani Zouhour ${ }^{1}$, Krati Khadija $^{1}$, Oubaha Sofia ${ }^{2}$
}

\author{
${ }^{1}$ Departement of Hepato-Gastro-Enterology, Arrazi hospital, Mohammed VI University Hospital Center, Marrakech 40000, Morocco \\ ${ }^{2}$ Departement of Physiology, Faculty of Medicine, Cadi Ayyad University, Marrakech 40000, Morocco
}

DOI: $10.36347 /$ sjmcr.2020.v08i12.012

| Received: 19.11.2020 | Accepted: 02.12.2020 | Published: 26.12.2020

*Corresponding author: Chait Yassine

\section{Abstract}

Background: Eosinophilic esophagitis is a chronic, inflammatory disease characterized clinically by symptoms related to esophageal dysfunction and histologically by a marked eosinophilic infiltrate in the esophageal mucosa. It predominantly occurs in young men with a history of atopy. Dysphagia and food impaction are the most common presentations. Case presentation: A 35-year-old man with known history of recurrent allergic rhinitis, presented with recurrent dysphagia reveling food impaction. Esophageal biopsies showed eosinophilic polynuclear exocytosis. Avoiding the responsible allergens, as well as topical corticosteroid therapy improved the patient's symptoms. Conclusion: Eosinophilic esophagitis is still poorly understood, It is more common in young men, and there is usually a marked atopic component. It is the leading cause of dysphagia and feeding impaction in young men. Depending on the case, patients may require multidisciplinary treatment by gastroenterologists, allergists, immunologists and nutritionists.

Keywords: Eosinophilic esophagitis, Dysphagia, corticosteroid therapy.

Copyright $\odot 2020$ The Author(s): This is an open-access article distributed under the terms of the Creative Commons Attribution 4.0 International License (CC BY-NC 4.0) which permits unrestricted use, distribution, and reproduction in any medium for non-commercial use provided the original author and source are credited.

\section{INTRODUCTION}

Eosinophilic oesophagitis is a chronic inflammatory pathology characterised by isolated dense infiltration of the oesophageal mucosa by eosinophils, associated with high digestive symptoms, unrelated to any other cause [1].

The pathogenesis is still poorly known, but it is an allergic-type disease, the allergens can be either food or aeroallergens. It is the immune response mediated by Th2 lymphocytes that seems to be responsible for this pathology, with the increase in pro-inflammatory mediators (interleukin 4, 5, 13 and eotaxin) recruiting eosinophils [2].

\section{ObServation}

A 35 year old man with a history of recurrent allergic rhinitis episodes presented with iterative and paroxysmal episodes of high dysphagia for two years.

Dysphagia occurred after food intake and predominated over solids. Clinical examination and standard laboratory tests were normal.
Esophageal endoscopy found a foreign food body upstream of a narrowed aspect of the esophageal lumen in the middle third of the esophagus. An extraction of food residue was carried out to complete the assessment.

A biological assessment was requested and did not show any abnormalities. A cervicothoracic scan showed a corrugated and isolated arrangement of the middle oesophagus. Esophageal manometry did not identify any motor disorders.

The patient was then lost to follow-up before returning to the emergency room for a worsening dysphagia. On questioning, the patient reported a predominantly solids dysphagia in solids, with worsening episodes lasting 2 years.

The endoscopy revealed esophageal food foreign body impaction, after extraction of food residues in the middle third; we revealed an erythematous and congestive esophageal mucosa. The gastroduodenal examination was normal. 


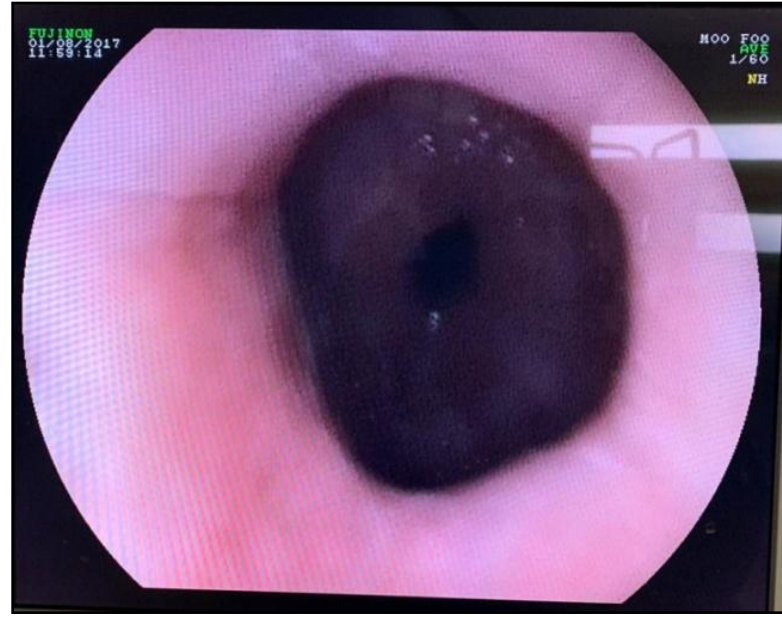

Fig-1: Endoscopic aspect of the esophagus

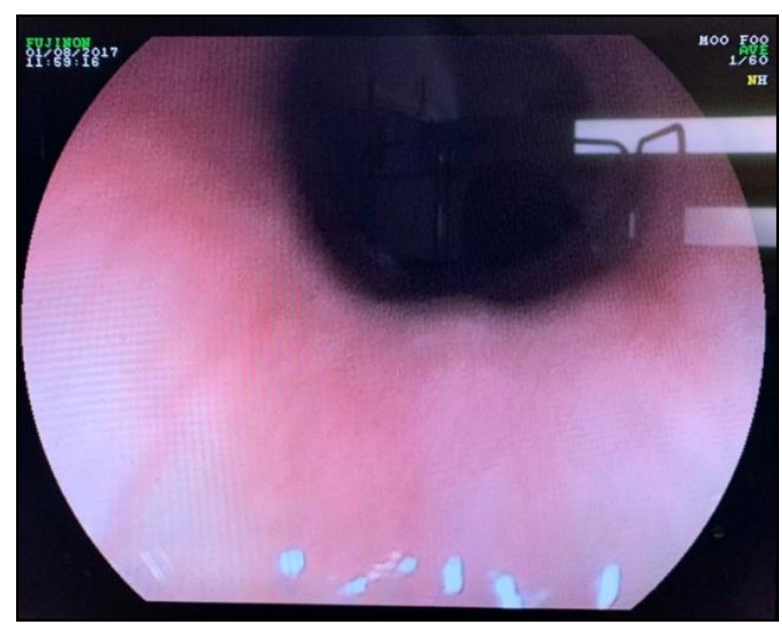

Fig-2: Endoscopic aspect of the esophagus

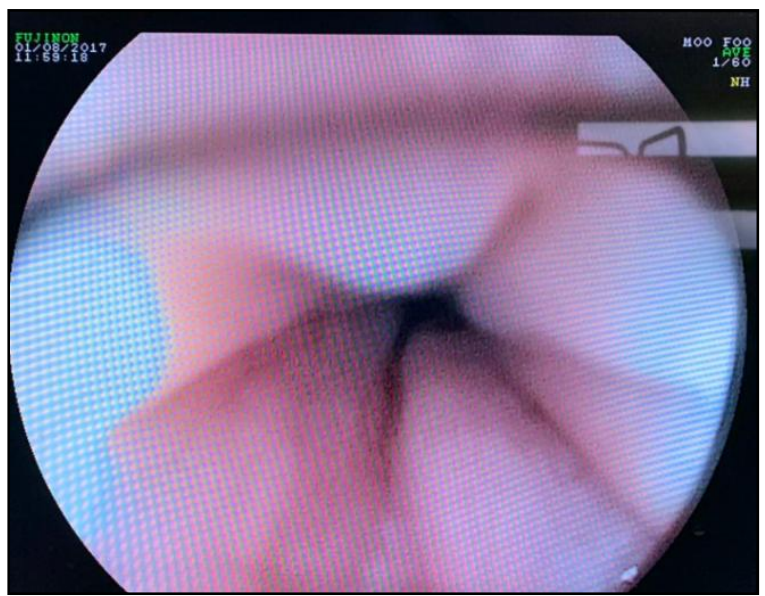

Fig-3: Endoscopic aspect of the esophagus

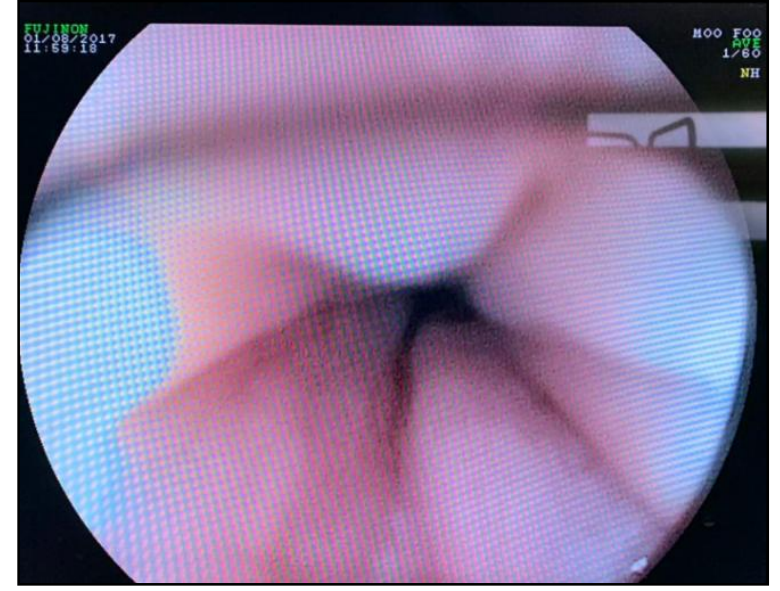

Fig-4: Endoscopic aspect of the esophagus

Staged esophageal biopsies showed eosinophilic polynuclear exocytosis at a rate of 30 intraepithelial eosinophilic polynuclear cells per field at high magnification which led to the diagnosis of eosinophilic esophagitis.

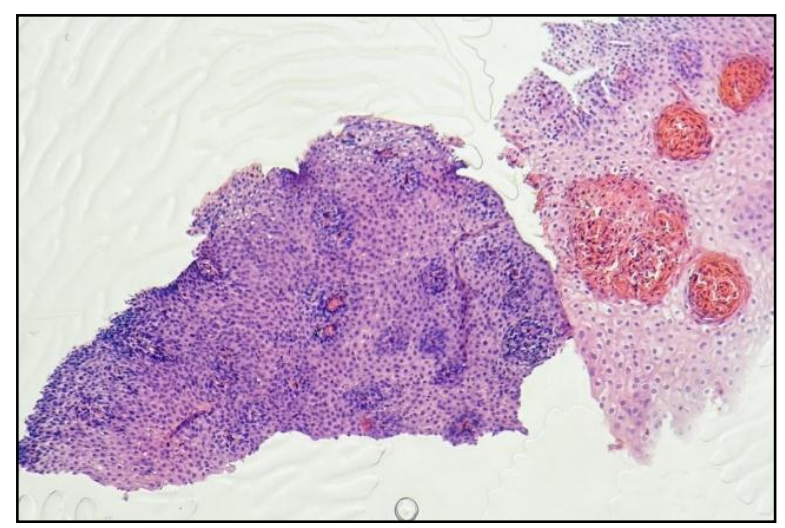

Fig-5: Histological features suggestive of eosinophilic esophagitis

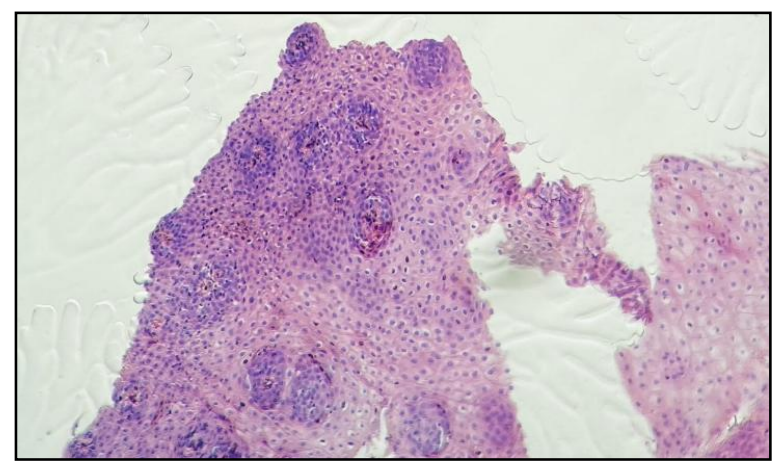

Fig-6: Histological features suggestive of eosinophilic esophagitis 


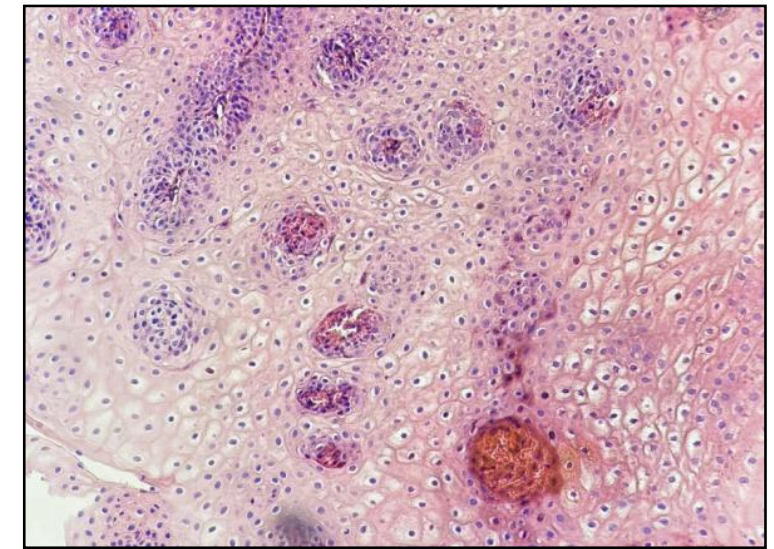

Fig-7: Histological features suggestive of eosinophilic esophagitis

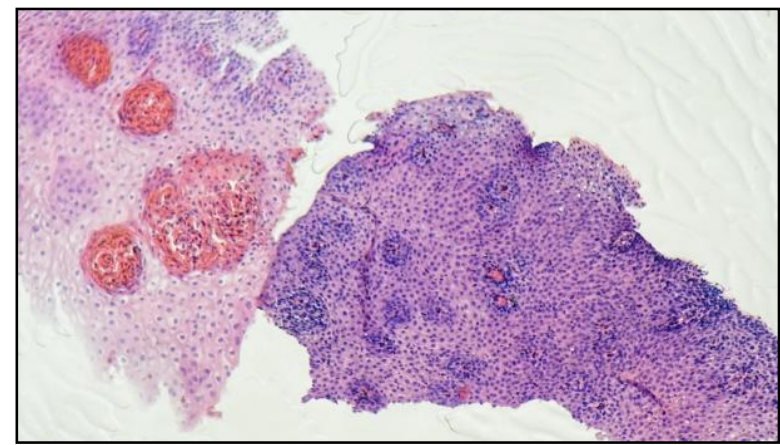

Fig-8: Histological features suggestive of eosinophilic esophagitis

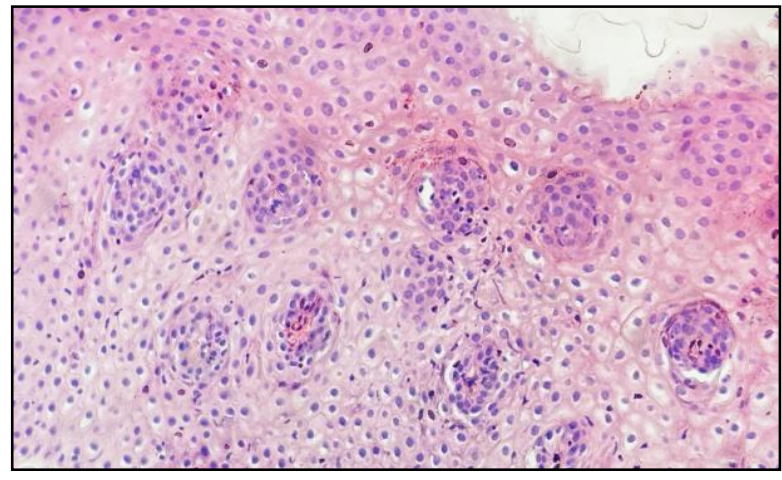

Fig-9: Histological features suggestive of eosinophilic esophagitis

A biological assessment was requested and revealed an Hb: $14.1 \mathrm{~g} / \mathrm{dl}$ GB: 12000 ele/mm3 with hyperereosinophilia at PNE: 540 ele/mm3 and PLQ: $250000 \mathrm{ele} / \mathrm{mm} 3$, renal function as well as the ionogram blood were without abnormalities.

The blood dosage of Total IgE returned slightly increased to $250 \mathrm{kU} / \mathrm{L}$. The diagnosis of eosinophilic esophagitis was retained. In addition, the patient was referred to allergology in order to search for a possible allergen responsible for the aggravation of the symptoms. The prick test and patch test revealed sensitivity to mites, pollens and cockroaches.
The management of our patient consisted first of all in avoiding the responsible allergens, moreover he was put on topical corticosteroid therapy with fluticasone ( $250 \mathrm{~g}$, two puffs per day) was started for an initial period of eight weeks. The patient remained asymptomatic after 4 months of follow-up, and reported an improvement in his rhinitis.

\section{DISCUSSION}

Long considered a rare disease, eosinophilic esophagitis is experiencing a resurgence of interest due to an increase in its prevalence in industrialized countries, from $0.1 \%$ in 2001 to $1.9 \%$ in 2005 in the United States [3].

Adult eosinophilic esophagitis can occur at any age and in all ethnic groups, but predominates in Caucasian males between 30 and 40 years of age [4].

The male / female ratio is 3 to 1 . We often find an atopic or allergic ground, as well as a genetic predisposition $[5,6]$.

There is no increase in neoplastic risk or impact on life expectancy, despite an impact on quality of life [7].

Symptoms of eosinophilic esophagitis vary greatly with age. In small children, there is difficulty feeding and gaining weight. The older child complains of abdominal pain and vomiting, while adolescents, like adults, mainly complains of dysphagia with solids $(70 \%)$ and symptoms suggestive of gastroesophageal reflux $(40 \%)$ [8].

As with our patient It is often accompanied by episodes of food impaction. The other signs are hyper sialorrhea, vomiting, abdominal or chest pain, and heartburn. There is a long delay between the onset of symptoms and diagnosis $[1,9,10]$.

In the majority of cases, it is associated with atopic manifestations (asthma, rhinoconjunctivitis, eczema), another allergic pathology or food allergies. A family history of allergy is present in more than $40 \%$ of patients [11].

The biological 1 results are usually normal in patients with eosinophilic esophagitis. However, a few studies show a hypereosinophilia greater than 300-350/ $\mathrm{mm} 3$, which can affect up to $40-50 \%$ of patients. In this case, the age of the patient must be taken into account, and the possible presence of concomitant allergies (seasonal, airborne allergens). This slight rise in eosinophils is normalized under effective treatment [1].

The first examination requested should be a gastroscopy with biopsies, as the barium swallow does not make the diagnosis. Gastroscopy is therefore indispensable and must be accompanied in all cases by 
biopsies of the esophagus, even if the endoscopic appearance is normal [12].

In eosinophilic esophagitis, endoscopy is normal in about $10 \%$ of cases [13].

There are characteristic, but not pathognomonic, images of eosinophilic esophagitis. The esophagus may present with stenosis, circular ring appearances, reduced size of the esophagus, or unspecific whitish spots not suggestive of candidiasis. Finally, there may be some granularity of the mucosa or longitudinal striations, but the mucosa may also be completely normal. Biopsies should be taken from the lower and upper oesophagus. The pathologist will make the diagnosis by revealing a significant infiltration by eosinophils throughout the esophagus (more than 15 per field, at magnification $\mathrm{x}$ 400) [12].
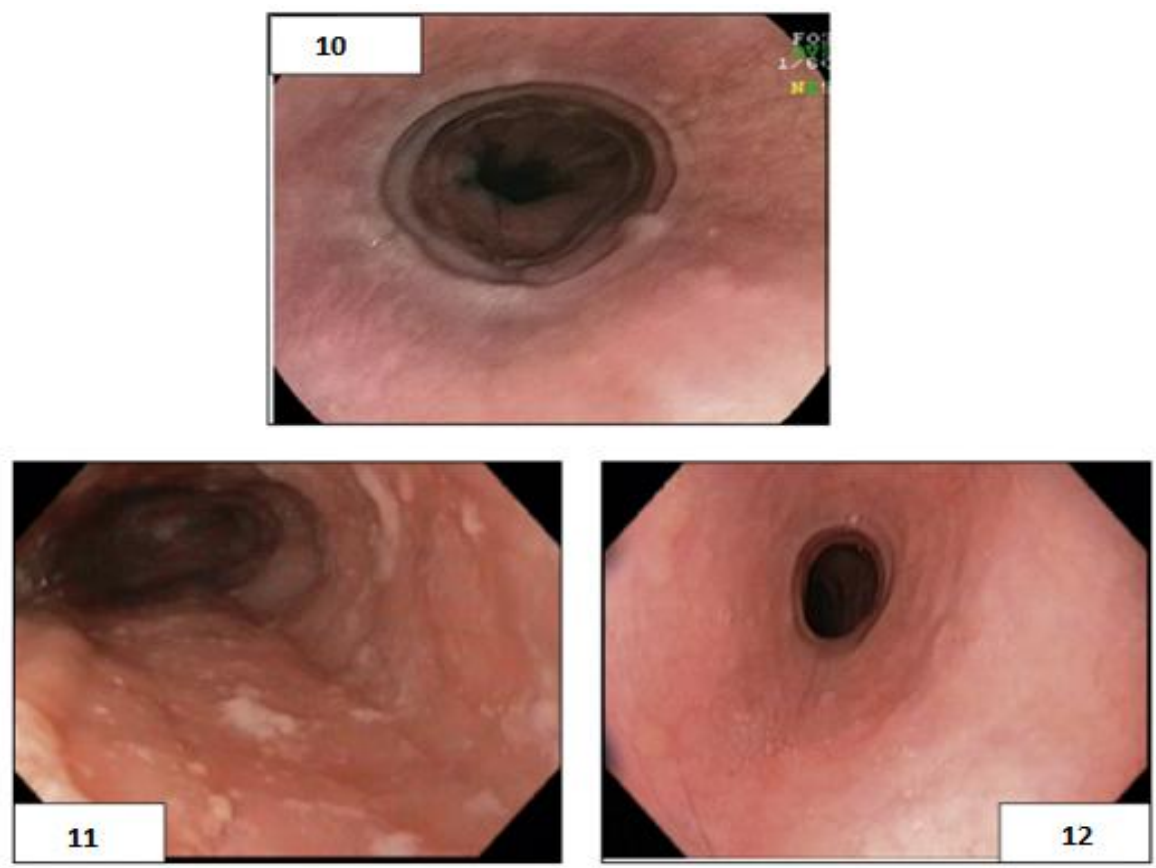

Figure 10-12: Endoscopic features suggestive of eosinophilic esophagitis A. Whitish deposits with streaky appearance. B. Ring aspect. C. Whitish appearance of the gastroesophageal junction [14]
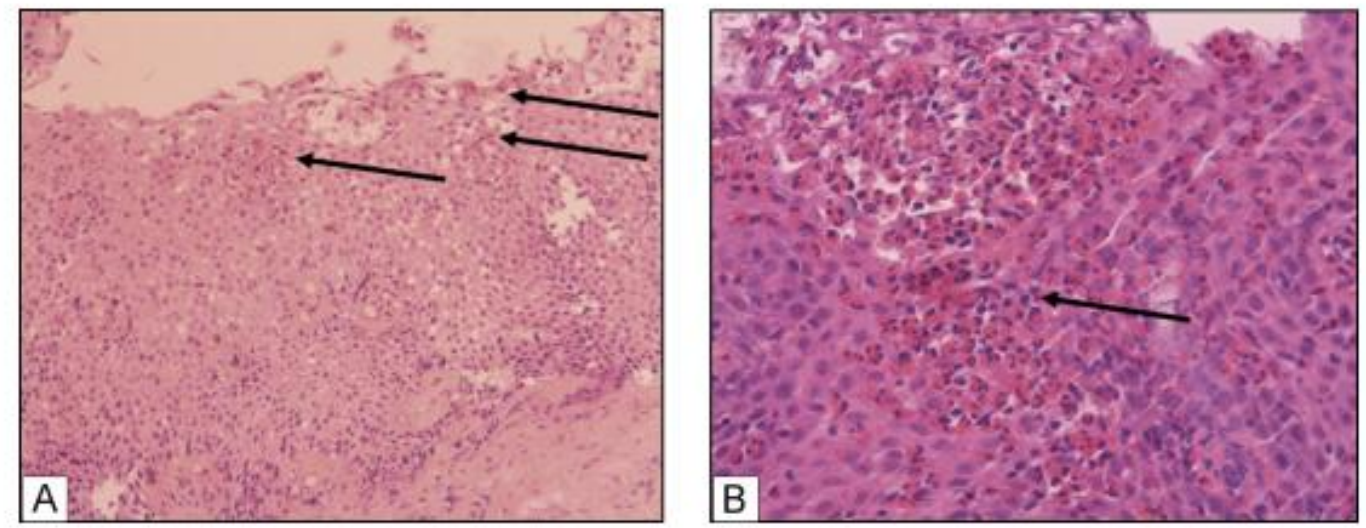

Fig-13: Histological features suggestive of eosinophilic esophagitis. HES A. Multiple eosinophils scattered in the superficial layers of the esophageal epithelium, HES 100. B. Microabscess of eosinophils on the surface of the esophageal epithelium, HES 400 [14]

It is sometimes difficult to tell the difference between eosinophilic esophagitis and genuine gastroesophageal reflux disease. In most studies, the distinction is based on the clinical and histological aspect. However, some forms of esophageal eosinophilia respond to treatment with a proton pump inhibitor and therefore should no longer be considered as eosinophilic esophagitis [15]. 
Treatment consists of eliminating allergens when they are identified. It combines topical corticosteroid therapy with budosenide ( $2 \mathrm{mg} /$ day) or fluticasone (500 to $1000 \mathrm{mg} / \mathrm{day}$ ) for six to eight weeks $[1,10,11,16]$.

Systemic corticosteroid therapy with predsinone is an alternative in case of failure or severe forms. The dosage is 1 to $2 \mathrm{mg} / \mathrm{kg}$ per day for eight weeks and then a gradual decrease over six weeks.

Other molecules are used in severe or corticosteroid-resistant forms: they are leukotriene antagonists (montelukast), immunosuppressants (azathioprine) and biotherapy (mepolizumab) [17].

\section{Conclusion}

Eosinophilic esophagitis is a recently recognized entity for which interest is growing. It is the leading cause of dysphagia and feeding impaction in young men.

The anatomoclinical forms are diverse and varied. It is important for gastroenterologists to think about when faced with any unexplained upper digestive tract symptoms, especially dysphagia. The performance of staged biopsies, in healthy and damaged areas, is of paramount interest in the diagnosis of eosinophilic esophagitis. Corticosteroid therapy is the reference treatment. Complications are rare, but recurrences are frequent. Regular endoscopic monitoring is not essential [17].

\section{REFERENCS}

1. Liacouras CA, Furuta GT, Hirano I, Atkins D, Attwood SE, Bonis PA, Burks AW, Chehade M, Collins MH, Dellon ES, Dohil R. Eosinophilic esophagitis: updated consensus recommendations for children and adults. Journal of Allergy and Clinical Immunology. 2011 Jul 1;128(1):3-20.

2. Atkins D, Kramer R, Capocelli K, Lovell M, Furuta GT. Eosinophilic esophagitis: the newest esophageal inflammatory disease. Nat Rev Gastroenterol Hepatol. 2009; 6(5):267.

3. Billot D, Pernin M, Pillot C, Bredin C, Hoeffler P, Graffin B, Rey P. Eosinophilic esophagitis: a rare cause of dysphagia. La Revue de medecine interne. 2010 Dec;31(12):e4-6.

4. Kapel RC, Miller JK, Torres C, Aksoy S, Lash R, Katzka DA. Eosinophilic esophagitis: a prevalent disease in the United States that affects all age groups. Gastroenterology. 2008; 134(5):13161321.

5. Blanchard C, Wang N, Rothenberg ME. Eosinophilic esophagitis: pathogenesis, genetics, and therapy. J Allergy Clin Immunol. 2006; 118(5):1054-1059.

6. Parfitt JR, Gregor JC, Suskin NG, Jawa HA, Driman DK. Eosinophilic esophagitis in adults: distinguishing features from gastroesophageal reflux disease: a study of 41 patients. Mod Pathol. 2006;19(1):90-96.

7. Straumann A, Spichtin HP, Grize L, Bucher KA, Beglinger C, Simon HU. Natural history of primary eosinophilic esophagitis: a follow-up of 30 adult patients for up to 11.5 years. Gastroenterology. Déc 2003; 125(6):1660 - 9.

8. Yan BM, Shaffer EA. Primary eosinophilic disorders of the gastrointestinal tract. Gut. 2009; 58(5):721-732.

9. Pasha SF, Crowell MD, Alexander JA, Harris LA, Achem SR, Farrugia G, Lee JJ, Thompson DM, Jung KW, Kita H, Ravi K. Eosinophilic oesophagitis in adults-A rising epidemic. European Gastroenterology and Hepatology Review. 2011 Feb;7(1):14-20.

10. Remedios M, Campbell C, Jones DM, Kerlin P. Eosinophilic esophagitis in adults: clinical, endoscopic, histologic findings, and response to treatment with fluticasone propionate. Gastrointest Endosc. 2006;63(1):3-12.

11. Berthet S, Triolo V, Bourrier T, Descos B, De Smet S, Berard E. Eosinophilic esophagitis. Presentation, allergological assessment and treatment: about 22 cases. Arch Pediatrics. 2011; 18 (1): 7-14.

12. Cohen MS, Kaufman AB, Palazzo JP, Nevin D, DiMarino Jr AJ, Cohen S. An audit of endoscopic complications in adult eosinophilic esophagitis. Clin Gastroenterol Hepatol. 2007;5(10):11491153.

13. Abonia JP, Blanchard C, Butz BB, Rainey HF, Collins MH, Stringer K, Putnam PE, Rothenberg ME. Involvement of mast cells in eosinophilic esophagitis. Journal of Allergy and Clinical Immunology. $2010 \mathrm{Jul}$ 1;126(1):140-9.

14. Saillen É, Cellier C, Naneix A-L, Canioni D, Bruneval P, Pouchot J. Eosinophilic esophagitis. Medical Press. 2014; 43(1): 34-38.

15. Molina-Infante J, Ferrando-Lamana L, Ripoll C, Hernandez-Alonso M, Mateos JM, FernandezBermejo M. Esophageal eosinophilic infiltration responds to proton pump inhibition in most adults. Clin Gastroenterol Hepatol. 2011;9(2):110-117.

16. Sgouros SN, Bergele C, Mantides A. Eosinophilic esophagitis in adults: a systematic review. Eur J Gastroenterol Hepatol Févr. 2006;18(2):211- 7.

17. Halim A, Diallo S, Bassčne ML, Dia D, Bčye B, Mbemgue M. Eosinophilic esophagitis in black Africans: a case report. J Afr HepatoGastroenterology. 2016;10(4): 227-228. 